Research Article

\title{
Design of a Third-party Reverse Logistics Network under a Carbon Tax Scheme
}

\author{
Cheng-Hu Yang ${ }^{1}$, Du-Tian Chen ${ }^{1}$, Zhui-Liang Huang ${ }^{1, *}$ and Hai-Bo Liu ${ }^{2}$ \\ ${ }^{1}$ School of Economics \& Management, Fuzhou University, Fuzhou, 350108, P. R. China \\ ${ }^{2}$ Marketing Discipline Group, Business School, University of Technology Sydney, NSW, 2007, Australia
}

Received 1 August 2016; Accepted 26 October 2016

\begin{abstract}
Reverse logistics network involves significant inherent uncertainties, which cannot be completely characterized because of a lack of adequate historical data. In this study, a multi-product and multi-period interval programming model was developed on the basis of partial information to design an effective reverse logistics network. In addition, the trade-off between economic benefits and the environmental burdens from carbon emissions was analyzed by considering the effect of a carbon tax scheme on the reverse logistics network design. Through an improved and modified interval linear programming method, the optimal interval solution was obtained with LINGO. Finally, numerical simulations were conducted to explore the effectiveness of the model and the effect of the carbon tax scheme. Results show that the optimal solution of the reverse logistics network design is robust. The effect of the carbon tax scheme is trivial when the carbon tax is low and significant when the carbon tax is high. As carbon tax gradually increases, carbon emissions effectively decrease, but sharply declines the total profit sharply declines. The findings indicate that the proposed model can effectively solve the reverse logistics network design with partial information under a carbon tax scheme.
\end{abstract}

Keywords: Waste Household Appliances, Reverse Logistics Network, Carbon Emissions, Interval Programming

\section{Introduction}

With the rapid updating of products, the waste of electrical and electronic equipment results in considerable resource wastage and serious environmental pollution and potential safety hazards [1]. Reverse logistics, as an important measure of product and material recovery, can increase firms' environmental performance and create competitive advantages for them [2]. Reverse logistics networks are adopted to recover used products from target consumers, test and sort these used products, and then return them to recycling sites. In reverse logistics, network design is one of the most challenging issues and has thus attracted increasing attention worldwide.

In practice, the quantity and quality of acquirable waste household appliances and second-hand electric appliance markets are highly variable. Moreover, reverse logistics activities largely depend on high uncertainties. In traditional decisions, these uncertainties are represented by stochastic variables with known distribution functions or fuzzy variables with fuzzy membership functions of parameters [3], [4]. Such setup implies that firms can obtain full knowledge of uncertainties. However, firms cannot easily gather adequate historical data to characterize these uncertainties. Only partial information may be obtained, but it is challenging to use when deriving effective decisions about reverse logistics network design. In this case, uncertainties can be described by interval variables because of limited historical data. Moreover, flexible interval solutions can easily be obtained through interval programming. Hence, in the present study, an interval

\footnotetext{
*E-mail address: hzl@fzu.edu.cn

ISSN: 1791-2377 @ 2016 Eastern Macedonia and Thrace Institute of Technology. All rights reserved.
}

programming model is considered to be applied in the reverse logistics network design.

In operations management, "The environmental burdens associated with energy consumption, material consumption, air emissions, and solid waste generation usually are ignored" [5]. These burdens exert a significant influence on reverse logistics activities [6]. Carbon emissions, as classic environmental burdens, have received considerable attention from researchers [7]. In the current work, the effect of carbon emissions is incorporated into the reverse logistics network design on the basis of a carbon tax scheme.

\section{State of the art}

In reverse logistics research, the topics mainly include reverse logistics network design, hybrid inventory management, vehicle routing, and production scheduling [8], [9], [10], [11], [12]. As an important research issue, reverse logistics network design has been widely studied. For example, Jayaraman et al. developed strong and weak mathematical programming formulations for the design of reverse distribution networks and provided an effective heuristic solution methodology [13]. Kara et al. proposed a simulation model to study the reverse logistics networks of end-of-life appliances in the Sydney Metropolitan Area [14]. Sheu studied a coordinated reverse logistics management system and formulated a linear multi-objective model to minimize the total reverse logistics operating costs and corresponding risks [15]. Hatefi and Jolai proposed a robust and reliable model for an integrated forward-reverse logistics network design that considers both uncertain parameters and facility disruptions [16]. Govindan et al. applied fuzzy mathematical programming to design a multiechelon, multi-period, multi-objective model for a 
sustainable reverse logistics network. In this model, environmental, social, and economic indicators are considered [17]. However, the aforementioned studies investigated the reverse logistics network design from the perspective of manufacturers. Moreover, this body of research ignored the effect of third-party logistics (3PL) service providers.

In practice, an increasing number of firms outsource their reverse logistics business to 3PL service providers [18]. Professional 3PL service providers can normalize reverse logistics activities, reduce operational risks and costs, and improve operation efficiency; thus, they offer great practical significance by improving the market competitiveness of enterprises. Hyun and Evans proposed a multi-period and two-echelon location distribution model to design the forward and reverse network of a 3PL service provider [19]. Suyabatmaz et al. presented hybrid simulation-analytical modeling approaches for the reverse logistics network design of a 3PL service provider. They obtained the numbers and places of test centers under the uncertainty of the quantity of acquirable used products [1]. Ayvaz et al. proposed a generic multi-echelon, multi-product, and capacity-constrained two-stage stochastic programming model to study the reverse logistics network design for the third-party waste of electrical and electronic equipment recycling companies [2].

High uncertainties are a crucial feature of reverse logistics activities [20], [21]. According to the existing literature, information about uncertainties can be perfectly obtained by firms before making decisions. Specifically, uncertainties are usually expressed as stochastic variables with known distribution functions or fuzzy variables with fuzzy membership functions of parameters [3], [4]. In practice, some partial information about uncertainties, such as range, mean, and variance, is easily obtained. Thus, designing reverse logistics network with partial information is realistic. Moreover, interval programming is an important method to process partial information in operations management [22], [23].

The carbon emissions of reverse logistics activities should not be ignored. Krikke studied the effects of closedloop copier network configurations on carbon footprints and pointed out that a regional network with forward and reverse facilities is most efficient and most robust under uncertain environments [24]. Kannan et al. developed a mixed integer linear model to study reverse logistics network design based on carbon footprints with the goal of minimizing the total cost involved in reverse logistics activities and the emissions resulting from logistics and facilities [25]. However, a comprehensive knowledge of uncertainties is assumed to exist in the existing literature.

According to the above analysis, a multi-product and multi-period interval programming model is established in the present work to study the reverse logistics network design with $3 \mathrm{PL}$ service providers. In the model, the uncertainties of recycling quantity, recycling quality, and secondary market demands are represented by interval variables. In addition, numerical simulations are performed to illustrate the model and the approach with managerial insights.

The rest of this paper is organized as follows. In Section 3 , the problem statement is detailed, and an interval programming model is formulated. Moreover, an improved and modified interval linear programming method is developed to obtain the interval solution. In Section 4, numerical examples are given to illustrate the model and the solution with managerial insights. In Section 5, the conclusion of the study and future research directions are presented.

\section{Methodology}

\subsection{Problem Descriptions and Assumptions}

This study investigates a reverse logistics network for waste household appliances, which consists of recycle points, transfer stations, recycle centers, second-hand electric appliance markets, raw material markets, part reproducing factories, and waste treatment plants (Fig. 1).

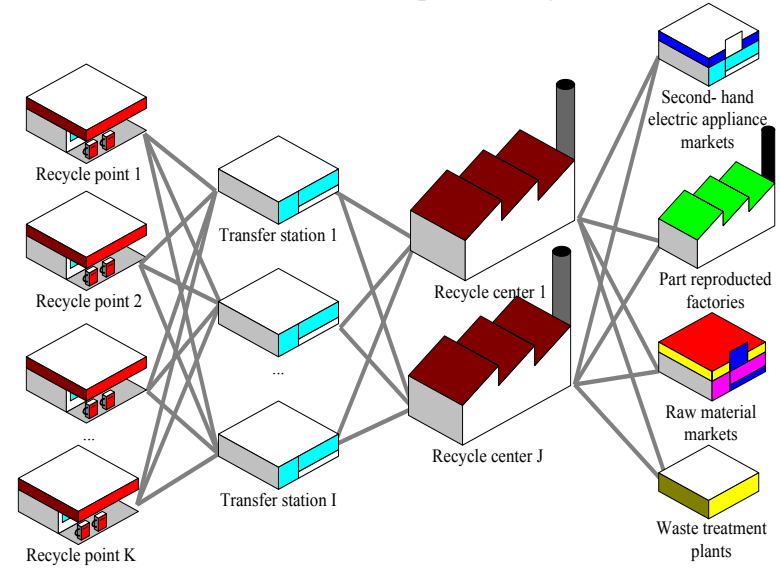

Fig.1. Structure of the 3PL reverse logistics network for waste household appliances

To balance economic benefits and the environmental burdens from carbon emissions, this study develops a multiproduct and multi-period reverse 3PL logistics network model, through which the optimal locations of 3PL service providers and the returned product flows among different service providers can be obtained.

Given the difficulty in collecting adequate historical data for assessing the uncertainties of the 3PL reverse logistics network (i.e., recycling quantity, gradient utilizations, and secondary household appliance market demand), the uncertain parameters are represented by interval variables. According to [22], the interval variable $t$ is denoted by $x^{ \pm}=\left[x^{-}, x^{+}\right]=\left[t \in x \mid x^{-} \leq t \leq x^{+}\right]$, where $x^{-}$is the lower bound of the interval and $x^{+}$is the upper bound of the interval.

The following assumptions are also derived:

(1) The alternative locations of 3PL service providers are known.

(2) Recycling zoning is fixed. Each recycling region comprises one corresponding recycle point.

(3) Transfer stations delivers waste household appliances received from recycle points to recycle centers immediately after simple classification. Transfer centers do not provide storage capacity. In addition, the transportation cost per unit product and distance between network nodes is fixed.

(4) Recycle centers have limited processing capacity. Returned products beyond the maximum processing capacity are left to be handled in the next period.

(5) The carbon emissions in different stages (i.e., acquisition, transport, reuse, recycle, and disposition) are considered simultaneously. 
(6) A carbon tax scheme is a frequently used costeffective means for reducing carbon emissions. The corresponding effects of the carbon tax scheme are analyzed

\subsection{Model Parameters and Decision Variables}

\subsubsection{Indices}

$t$ : Planning horizon, $t \in\{1,2, \ldots, T\}$.

$p$ : Set of waste household appliance categories, $p \in\{1,2, \ldots, P\}$.

$k$ : Set of recycle points, $k \in\{1,2, \ldots, K\}$.

$i$ : Alternative transfer station locations, $i \in\{1,2, \ldots, I\}$.

$j$ : Alternative recycle center locations, $j \in\{1,2, \ldots, J\}$.

$m$ : Set of secondary household appliance markets, $m \in\{1,2, \ldots, M\}$.

$s$ : Set of raw material markets, $s \in\{1,2, \ldots, S\}$.

$r$ : Set of reproducing factories, $r \in\{1,2, \ldots, R\}$

$n$ : Alternative locations of treatment plants for waste household appliances, $n \in\{1,2, \ldots, N\}$.

$c$ : Set of raw material categories of recycled waste household appliances, $c \in\{1,2, \ldots, C\}$.

$d$ : Set of part categories of recycled waste household appliances, $d \in\{1,2, \ldots, D\}$.

\subsubsection{Parameters}

$S_{p}$ : Unit price of category $p$ second-hand household appliance reused directly.

$S_{d}^{r e m}$ : Unit price of category $d$ produced part.

$S_{c}$ : Unit price of category $c$ raw material.

$c_{p}^{d i s}$ : Unit reuse cost of category $p$ second-hand household appliance.

$c_{d}^{\text {rem }}$ : Unit reproducing cost of category $d$ produced part.

$c_{c}^{\text {dis }}$ : Unit disposing cost of category $c$ raw material.

$c_{k p}, c_{i p}, c_{j p}:$ Unit disposing cost of category $p$ second-hand household appliance on recycle point $k$, transfer station $i$, and recycle center $j$, respectively.

$c_{n}$ : Unit average treatment cost of waste treatment plant $n$.

$f_{i}, f_{j}$ : Fixed cost of open transfer station $i$ and recycle center $j$, respectively.

$c_{p}, S_{t p k}^{ \pm}$: Unit acquisition price and quantity of category $p$ waste household appliance products that can be collected from recycle point $k$ in $t$, respectively.

$c_{k p}^{g o v}$ : Government subsidies of category $p$ waste household appliance products for recycle points.

$c_{i p}^{g o v}$ : Government subsidies of category $p$ waste household appliance products for transfer stations.

$c_{j p}^{g o v}$ : Government subsidies of category $p$ waste household appliance products for recycle centers.

$c_{m p}^{g o v}$ : Government subsidies of category $p$ waste household appliance products for secondary markets.

$c_{s c}^{g o v}$ : Government subsidies of category $c$ raw materials for raw material markets. $c_{r d}^{g o v}$ : Government subsidies of category $d$ produced parts for part reproducing factories.

$c_{n}^{g o v}$ : Government subsidies of treatment waste products for waste treatment plants.

$e_{m}$ : Unit carbon emission of second-hand household appliance reused directly.

$e_{r}$ : Unit carbon emission of produced parts.

$e_{s}:$ Unit carbon emission of raw materials.

$e_{n}$ : Unit carbon emission of waste products.

$c_{e}:$ Carbon tax of unit carbon emission.

tc: Unit transportation cost.

$d_{k i}$ : Distance from recycle point $k$ to transfer station $i$.

$d_{i j}$ : Distance from transfer station $i$ to recycle center $j$.

$d_{j m}, d_{j r}, d_{j s}, d_{j n}$ : Distances from recycle center $j$ to secondary household appliance market $m$, reproducing plant $r$, raw material market $s$, and waste treatment plant $n$, respectively.

$\mathrm{Cap}_{i}^{\text {min }}, \mathrm{Cap}_{i}^{\text {max }}, \mathrm{Cap}_{j}^{\text {min }}, \mathrm{Cap}_{j}^{\text {max }}, \mathrm{Cap}_{n}^{\text {min }}, \mathrm{Cap}_{n}^{\text {max }}:$ Minimum and maximum processing capacities of different service providers.

$Q_{m}^{\max }, Q_{s}^{\max }, Q_{r}^{\max }:$ Maximum demands of secondary household appliance market $m$, raw material market $s$, and part reproducing plant $r$, respectively.

$d^{2 e m_{t p m}^{ \pm}}=$Average demand of secondary household appliance market $m$.

$\delta_{p}^{ \pm}, \beta_{p}^{ \pm}, \gamma_{p}^{ \pm}, \varepsilon_{p}^{ \pm}$: Proportions of category $p$ waste household appliance products that can be reused directly, recycled, reproduced, and disposed, respectively.

$\eta_{c p}, \eta_{d p}, g_{p}$ : Weight ratio of recycled raw material $c$, reproduced part $d$, and disposed product in category $p$ waste household appliances.

$s c_{j p}$ : Unit storage cost of category $p$ waste household appliances in recycle center $j$.

$M_{j p}^{ \pm}$: Maximum disposing capacity of category $p$ waste household appliances in recycle center $j$.

$S_{t j p}^{ \pm}$: Inventory of category $p$ waste household appliances in recycle center $j$ at the end of $t$.

$\pi_{t p m}^{ \pm}$: Unit shortage cost of category $p$ second-hand household appliances in secondary market $m$ in $t$.

$G$ : Maximum quantity of alternative transfer stations.

$Z$ : Maximum quantity of alternative recycle centers.

\subsubsection{Decision Variables}

$Y_{i}$ : Whether transfer station $i$ is open. If yes, $Y_{i}=1$; otherwise, $Y_{i}=0$.

$Y_{j}:$ Whether recycle center $j$ is open. If yes, $Y_{j}=1$; otherwise, $Y_{j}=0$. 
$Y_{n}:$ Whether wastes are transported to waste treatment plant $n$. If yes, $Y_{n}=1$; otherwise, $Y_{n}=0$.

$X_{t p k i}^{ \pm}$: Quantity of category $p$ waste household appliances transported from recycle point $k$ to transfer station $i$ in $t$.

$X_{t p i j}^{ \pm}$: Quantity of category $p$ waste household appliances transported from transfer station $i$ to recycle center $j$ in $t$.

$X_{t p j m}^{ \pm}$: Quantity of category $p$ waste household appliances transported from recycle center $j$ to secondary market $m$ in $t$. $X_{t c i s}^{ \pm}$: Quantity of category $c$ raw materials transported from recycle center $j$ to raw material market $s$ in $t$.

$X_{t d i r}^{ \pm}$: Weight of category $d$ parts transported from recycle center $j$ to reproducing plant $r$ in $t$.
$X_{t j n}^{ \pm}$: Weight of products transported from recycle center $j$ to waste treatment plant $n$ in $t$.

$V_{t j p}^{ \pm}$: Quantity of category $p$ waste household appliances processed by recycle center $j$ in $t$.

$\sigma_{t p m}^{ \pm}$: Shortage quantity of category $p$ household appliance products of secondary market $m$ in $t$.

\subsection{Model Formulation}

A multi-product and multi-period model is proposed as follows:

$$
\begin{aligned}
& \operatorname{MaxF}^{ \pm}=\sum_{t} \sum_{p} \sum_{k} S_{t p k}^{ \pm} \cdot c_{k p}^{g o v}+\sum_{t} \sum_{p} \sum_{k} \sum_{i} X_{t p k i}^{ \pm} \cdot c_{i p}^{g o v}+\sum_{t} \sum_{p} \sum_{i} \sum_{j} X_{t p i j}^{ \pm} \cdot c_{j p}^{g o v} \\
& +\sum_{t} \sum_{p} \sum_{j} \sum_{m} X_{t p j m}^{ \pm} \cdot c_{m p}^{g o v}+\sum_{t} \sum_{d} \sum_{j} \sum_{r} X_{t d j r}^{ \pm} \cdot c_{r d}^{g o v}+\sum_{t} \sum_{c} \sum_{j} \sum_{s} X_{t c j s}^{ \pm} \cdot c_{s c}^{g o v} \\
& +\sum_{t} \sum_{j} \sum_{n} X_{t j n}^{ \pm} \cdot c_{n}^{g o v}+\sum_{t} \sum_{p} \sum_{j} \sum_{m}\left(S_{p}-c_{p}^{d i s}\right) \cdot X_{t p j m}^{ \pm}+\sum_{t} \sum_{d} \sum_{j} \sum_{r}\left(S_{d}^{r e m}-c_{d}^{r e m}\right) \cdot X_{t d j r}^{ \pm} \\
& +\sum_{t} \sum_{c} \sum_{j} \sum_{s}\left(S_{c}-c_{c}^{d i s}\right) \cdot X_{t c j s}^{ \pm}-\sum_{t} \sum_{p} \sum_{k} c_{k p} \cdot S_{t p k}^{ \pm}-\sum_{t} \sum_{p} \sum_{k} \sum_{i} c_{i p} \cdot X_{t p k i}^{ \pm}-\sum_{t} \sum_{p} \sum_{j} c_{j p} \cdot V_{t j p}^{ \pm} \\
& -\sum_{t} \sum_{j} \sum_{n} c_{n} \cdot X_{t j n}^{ \pm}-\sum_{t} \sum_{p} \sum_{k} c_{p} \cdot S_{t p k}^{ \pm}-\sum_{t} \sum_{p} \sum_{k} \sum_{i} X_{t p k i}^{ \pm} \cdot g_{p} \cdot d_{k i} \cdot t c-\sum_{t} \sum_{c} \sum_{j} \sum_{s} X_{t c j s}^{ \pm} \cdot d_{j s} \cdot t c \\
& -\sum_{t} \sum_{p} \sum_{i} \sum_{j} X_{t p i j}^{ \pm} \cdot g_{p} \cdot d_{i j} \cdot t c-\sum_{t} \sum_{d} \sum_{j} \sum_{r} X_{t d j r}^{ \pm} \cdot d_{j r} \cdot t c-\sum_{t} \sum_{p} \sum_{j} \sum_{m} X_{t p j m}^{ \pm} \cdot g_{p} \cdot d_{j m} \cdot t c \\
& -\sum_{t} \sum_{j} \sum_{n} x_{t j n}^{ \pm} \cdot d_{j n} \cdot t c-\sum_{t} \sum_{p} \sum_{j} S_{t p j}^{ \pm} \cdot s c_{j p}-\sum_{t} \sum_{p} \sum_{m} \pi_{t p m} \cdot \sigma_{t p m}^{ \pm}-\sum_{i} f_{i} \cdot Y_{i}-\sum_{j} f_{j} \cdot Y_{j} \\
& -c_{e} \cdot\left(\sum_{t} \sum_{p} \sum_{j} \sum_{m} X_{t p j m}^{ \pm} \cdot e_{m}+\sum_{t} \sum_{d} \sum_{j} \sum_{r} X_{t d j r}^{ \pm} \cdot e_{r}+\sum_{t} \sum_{c} \sum_{j} \sum_{s} X_{t c j s}^{ \pm} \cdot e_{s}+\sum_{t} \sum_{j} \sum_{n} x_{t j n}^{ \pm} \cdot e_{n}\right)
\end{aligned}
$$

s.t.

$\sum_{i} X_{t p k i}^{ \pm}=S_{t p k}^{ \pm} \forall t, p, k$

$$
\sum_{k} X_{t p k i}^{ \pm}=\sum_{j} X_{t p i j}^{ \pm} \forall t, p, i
$$

$\sum_{i} X_{t p i j}^{ \pm}=V_{t j p}^{ \pm} \forall t, p, j$

$$
\begin{aligned}
& \sum_{s} X_{t c j s}^{ \pm}=\left\{\begin{array}{l}
\beta_{p}^{ \pm} \cdot\left(V_{t j p}^{ \pm}+S_{(t-1) j p}^{ \pm}-S_{t j p}^{ \pm}\right) \cdot g_{p} \cdot \eta_{c p}, t>1 \\
\beta_{p}^{ \pm} \cdot\left(V_{t j p}^{ \pm}-S_{t j p}^{ \pm}\right) \cdot g_{p} \cdot \eta_{c p}, t=1
\end{array} \quad \forall t, c, j\right. \\
& \sum_{r} X_{t d j r}^{ \pm}=\left\{\begin{array}{l}
\gamma_{p}^{ \pm} \cdot\left(V_{t j p}^{ \pm}+S_{(t-1) j p}^{ \pm}-S_{t j p}^{ \pm}\right) \cdot g_{p} \cdot \eta_{d p}, t>1 \\
\gamma_{p}^{ \pm} \cdot\left(V_{t j p}^{ \pm}-S_{t j p}^{ \pm}\right) \cdot g_{p} \cdot \eta_{d p}, t=1
\end{array} \quad \forall t, d, j\right. \\
& \sum_{n} X_{t j n}^{ \pm}=\left\{\begin{array}{l}
\varepsilon_{p}^{ \pm} \cdot\left(V_{t j p}^{ \pm}+S_{(t-1) j p}^{ \pm}-S_{t j p}^{ \pm}\right) \cdot g_{p}, t>1 \\
\varepsilon_{p}^{ \pm} \cdot\left(V_{t j p}^{ \pm}-S_{t j p}^{ \pm}\right) \cdot g_{p}, t=1
\end{array} \quad \forall t, j\right.
\end{aligned}
$$$$
\sum_{m} X_{t p j m}^{ \pm}=\left\{\begin{array}{l}
\delta_{p}^{ \pm} \cdot\left(V_{t j p}^{ \pm}+S_{(t-1) j p}^{ \pm}-S_{t j p}^{ \pm}\right), t>1 \\
\delta_{p}^{ \pm} \cdot\left(V_{t j p}^{ \pm}-S_{t j p}^{ \pm}\right), t=1
\end{array}\right.
$$$$
\forall t, p, j
$$ 


$$
S_{t j p}^{ \pm}=\left\{\begin{array}{l}
\max \left(V_{t j p}^{ \pm}+S_{(t-1) j p}^{ \pm}-M_{j p}^{ \pm}, 0\right) t>1 \\
\max \left(V_{t j p}^{ \pm}-M_{j p}^{ \pm}, 0\right) t=1
\end{array} \quad \forall t, p, j\right.
$$$$
S_{T j p}^{ \pm}=0 \quad \forall j, p
$$$$
\sum_{j} X_{t p j m}^{ \pm}+\sigma_{t p m}^{ \pm} \geq d e m_{t p m}^{ \pm} \forall t, p, m
$$$$
\sum_{p} \sum_{k} X_{t p k i}^{ \pm} \leq \operatorname{Cap}_{i}^{\max } \cdot Y_{i} \quad \forall t, i
$$$$
\sum_{p} \sum_{k} X_{t p k i}^{ \pm} \geq \operatorname{Cap}_{i}^{\min } \cdot Y_{i} \quad \forall t, i
$$$$
\sum_{p} \sum_{i} X_{t p i j}^{ \pm} \leq \operatorname{Cap}_{j}^{\max } \cdot Y_{j} \quad \forall t, j
$$$$
\sum_{p} \sum_{i} X_{t p i j}^{ \pm} \geq \operatorname{Cap}_{j}^{\min } \cdot Y_{j} \quad \forall t, j
$$$$
\sum_{j} X_{t j n}^{ \pm} \leq \operatorname{Cap}_{n}^{\max } \cdot Y_{n} \quad \forall t, n
$$$$
\sum_{j} X_{t j n}^{ \pm} \geq \operatorname{Cap}_{n}^{\min } \cdot Y_{n} \quad \forall t, n
$$$$
\sum_{j} X_{t p j m}^{ \pm} \leq Q_{m}^{\max } \quad \forall t, p, m
$$$$
\sum_{j} X_{t d j r}^{ \pm} \leq Q_{r}^{\max } \quad \forall t, d, r
$$$$
\sum_{j} X_{t c i s}^{ \pm} \leq Q_{s}^{\max } \quad \forall t, c, s
$$$$
1 \leq \sum_{i} Y_{i} \leq G
$$$$
1 \leq \sum_{j} Y_{j} \leq Z
$$$$
Y_{i}, Y_{j}, Y_{n} \in\{0,1\}
$$$$
X_{t p k i}^{ \pm}, X_{t p i j}^{ \pm}, X_{t c j s}^{ \pm}, X_{t p j m}^{ \pm}, X_{t j n}^{ \pm}, \sigma_{t p m}^{ \pm}, S_{t j p}^{ \pm} \geq 0
$$

The model (1) is aimed at maximizing the total profit of the reverse logistics network (i.e. Eq. (1)). In Eq. (1), the revenues include the government subsidies to different service providers and sales incomes from several markets. The costs include the disposing costs of different logistics service providers, waste treatment costs of treatment plants, collection costs of recycle points, transportation costs between facilities, storage costs of recycle centers, shortage costs of secondary household appliance markets, fixed costs of transfer stations and recycle centers, and carbon taxes of carbon emissions in different stages.
Constraints (2)-(4) ensure that the input is equal to the output in each recycle point and recycle center. Constraints (5)-(8) ensure that the output of each recycle center after gradient utilization is equal to the quantities of the available products from this recycle center. Constraint (9) means that the inventory only occurs when the input of the current period and the leftover inventory from the previous period exceed the maximum processing capacity of recycle centers. Constraint (10) indicates that the inventory at the end of the last period is 0. Constraint (11) is the constraint of reproduced products and the demands in the secondary household appliance markets. Constraints (12)-(17) denote the capacity limits of different service providers. Constraints (18)-(20) are the limits of different market demands. Constraints (21)-(22) are the quantity limits of alternative transfer stations and recycle centers. The value ranges of different variables are given in constraints (23)-(24).

\subsection{Solution}

The proposed model is an interval programming model. According to [23], the model can be solved with an improved and modified interval linear programming method. The upper-limit sub-model is first solved. Then, the lowerlimit sub-model is solved on the basis of the optimal solution of the upper-limit sub-model. Accordingly, the proposed model is decomposed into two separated submodels.

The upper-limit sub-model is given by

$$
\begin{aligned}
& \max f^{+}=\sum_{j=1}^{k_{1}} c_{j}^{+} x_{j}^{+}+\sum_{j=k_{1}+1}^{n} c_{j}^{+} x_{j}^{-} \\
& \text {s.t. } \\
& \sum_{j=1}^{k_{k}}\left|a_{i j}^{ \pm}\right|^{-} \operatorname{Sign}\left(a_{i j}^{ \pm}\right) x_{j}^{+}+\sum_{j=k_{1}+1}^{n}\left|a_{i j}^{ \pm}\right|^{+} \operatorname{Sign}\left(a_{i j}^{ \pm}\right) x_{j}^{-} \leq b_{i}^{+} \forall i
\end{aligned}
$$

$x_{j}^{ \pm} \geq 0 \quad \forall j$

where $x_{j}^{ \pm}\left(j=1,2, \ldots, k_{1}\right)$ and $x_{j}^{ \pm}\left(j=k_{1}+1, k_{1}+2, \ldots, n\right)$ are the interval variables of the positive and negative coefficients in the objective function. Sign is the sign function. If $a_{i j}$ is positive, it is expressed as 1 ; otherwise, it is expressed as -1 .

By solving the upper-limit sub-model, $x_{j, \text { opt }}^{+}\left(j=1,2, \ldots, k_{1}\right)$ and $x_{j, \text { opt }}^{-}\left(j=k_{1}+1, k_{1}+2, \ldots, n\right)$ are obtained. The lower-limit sub-model is given by

$$
\max f^{-}=\sum_{j=1}^{k_{1}} c_{j}^{-} x_{j}^{-}+\sum_{j=k_{1}+1}^{n} c_{j}^{-} x_{j}^{+}
$$

s.t.

$\sum_{j=1}^{k_{1}}\left|a_{i j}^{ \pm}\right|^{+} \operatorname{Sign}\left(a_{i j}^{ \pm}\right) x_{j}^{-}+\sum_{j=k_{1}+1}^{n}\left|a_{i j}^{ \pm}\right|^{-} \operatorname{Sign}\left(a_{i j}^{ \pm}\right) x_{j}^{+} \geq b_{i}^{-} \quad \forall i$

$x_{j}^{ \pm} \geq 0 \quad \forall j$ 


$$
\begin{aligned}
& x_{j}^{-} \leq x_{j, o p t}^{+} j=1,2, \ldots, k_{1} \\
& x_{j}^{+} \geq x_{j, o p t}^{-} j=k_{1}+1, k_{1}+2, \ldots, n \\
& \sum_{j=k-p+1}^{k}-\left(\left|a_{\delta j}^{ \pm}\right|^{+} x_{j}^{-}-\left|a_{\delta j}^{ \pm}\right|^{-} x_{j, o p t}^{+}\right) \\
& +\sum_{j=n=q+1}^{n}\left(\left|a_{\delta j}^{ \pm}\right|^{-} x_{j}^{+}-\left|a_{\delta_{j}}^{ \pm}\right|^{+} x_{j, o p t}^{-}\right) \leq 0 \quad \forall \delta \\
& f_{o p t}^{ \pm}=\left[f_{o p t}^{-}, f_{o p t}^{+}\right] \\
& x_{j, o p t}^{ \pm}=\left[x_{j, o p t}^{-}, x_{j, o p t}^{+}\right]
\end{aligned}
$$

As a result of space limitations in this study, we excluded a summary of the solutions. The corresponding details are available in [23].

\section{Result Analysis and Discussion}

\subsection{Parameter Setting}

The 3PL reverse logistics network is assumed to consist of four recycle points, three alternative transfer stations, two where $a_{\delta_{j}}^{ \pm} \geq 0$ for $j=1,2, \ldots, k-p, a_{\delta j}^{ \pm} \leq 0$ for $j=k-p+1, \ldots, k, k+1, \ldots, n-q \quad, \quad$ and $\quad a_{\delta j}^{ \pm} \geq 0 \quad$ for $j=n-q+1, \ldots, n$.

The optimal solutions (i.e., $x_{j, \text { opt }}^{-}\left(j=1,2, . ., k_{1}\right)$ and $x_{j, \text { opt }}^{+}\left(j=k_{1}+1, k_{1}+2, \ldots, n\right) \quad$ are obtained. The final interval solutions are

alternative recycle centers, three secondary household appliance markets, three part reproducing factories, four raw material markets, and two alternative waste treatment plants. In this network, two categories of products are disposed. Moreover, three categories of reproduced parts and five categories of recycled raw materials can be obtained. The carbon emissions in different stages are $e_{m}=e_{r}=e_{s}=0.2$

\begin{tabular}{|c|c|c|c|c|c|c|}
\hline${ }_{k} i$ & 1 & 2 & 3 & $T_{i}-j$ & 1 & 2 \\
\hline 1 & 3 & 3 & 4 & 1 & 22 & 23 \\
\hline 2 & 3 & 3 & 5 & 2 & 19 & 24 \\
\hline 3 & 5 & 3 & 6 & 3 & 20 & 26 \\
\hline 3 & 4 & 5 & 3 & & & \\
\hline
\end{tabular}
and $e_{n}=0.1$. The carbon tax of the unit carbon emission is $c_{e}=4$. The unit average treatment $\operatorname{cost} c_{n}=4.3(\$ / \mathrm{kg})$,

\begin{tabular}{|c|c|c|c|c|c|c|c|c|c|c|c|c|}
\hline \multirow{2}{*}{$j$} & \multicolumn{3}{|c|}{$m$} & \multicolumn{3}{|c|}{$r$} & \multicolumn{2}{|c|}{$n$} & \multicolumn{4}{|c|}{$S$} \\
\hline & 1 & 2 & 3 & 1 & 2 & 3 & 1 & 2 & 1 & 2 & 3 & 4 \\
\hline 1 & 22 & 19 & 20 & 3 & 67 & 31 & 101 & 83 & 18 & 67 & 31 & 54 \\
\hline 2 & 23 & 24 & 26 & 67 & 4 & 94 & 45 & 77 & 27 & 4 & 94 & 79 \\
\hline
\end{tabular}
and the unit transportation cost $t c=0.005(\$ / \mathrm{km} \mathrm{kg})$. The other parameters are shown in Tables 1-13.

Table 1. Parameter I $\left(d_{k i}\right.$ and $\left.d_{i j}\right)$

Table 2. Parameter II $\left(d_{j m}, d_{j r}, d_{j n}\right.$ and $\left.d_{j s}\right)$

\begin{tabular}{|c|c|c|c|c|c|c|}
\hline$i$ & 1 & 2 & 3 & $j$ & 1 & 2 \\
\hline $\mathrm{Cap}_{i}^{\min }$ & 4 & 5 & 5 & $\mathrm{Cap}_{j}^{\min }$ & 7 & 10 \\
\hline $\mathrm{Cap}_{i}^{\max }$ & 8 & 10 & 10 & $\mathrm{Cap}_{j}^{\max }$ & 14 & 20 \\
\hline$f_{i}$ & 500 & 480 & 490 & $f_{j}$ & 2400 & 2200 \\
\hline
\end{tabular}

Table 3. Parameter III $\left(S_{p}, c_{p}, c_{p}^{d i s}, s c_{i p}, g_{p}, c_{k p}, c_{i p}\right.$ and $\left.c_{j p}\right)$

\begin{tabular}{ccccccccc}
\hline $\begin{array}{c}\text { Appliance } \\
\text { Category }\end{array}$ & $S_{p}$ & $c_{p}$ & $c_{p}^{d i s}$ & $s c_{j p}$ & $g_{p}$ & $c_{k p}$ & $c_{i p}$ & $c_{j p}$ \\
\hline 1 & 250 & 150 & 30 & 7 & 35 & 2 & 2 \\
2 & 350 & 120 & 60 & 10 & 65 & 4 & 4 & 3 \\
\hline
\end{tabular}

Table 4. Parameter IV $\left(S_{d}^{r e m}, S_{c}, c_{d}^{r e m}, c_{c}^{d i s}, c_{r d}^{g o v}\right.$, and $\left.c_{s c}^{g o v}\right)$

\begin{tabular}{cccc|cccccc}
\hline Part & $\mathbf{1}$ & $\mathbf{2}$ & $\mathbf{3}$ & Raw material & $\mathbf{1}$ & $\mathbf{2}$ & $\mathbf{3}$ & $\mathbf{4}$ \\
\hline$S_{d}^{\text {rem }}$ & 28 & 18 & 30 & $S_{c}$ & 1.9 & 20 & 2.4 & 3.5 \\
$c_{d}^{r e m}$ & 12 & 6 & 13 & $c_{c}^{d i s}$ & 1.1 & 10 & 1.3 & 1.5 & 6 \\
$c_{r d}^{g o v}$ & 4 & 3 & 4 & $c_{s c}^{g o v}$ & 0.5 & 3 & 0.4 & 0.5 & 2 \\
\hline
\end{tabular}

Table 5. Parameter V $\left(\operatorname{Cap}_{i}^{\min }, \operatorname{Cap}_{i}^{\max }, \operatorname{Cap}_{j}^{\min }, \operatorname{Cap}_{i}^{\max }, \operatorname{Cap}_{n}^{\text {min }}, \operatorname{Cap}_{n}^{\max }, f_{i}, f_{j}\right.$, and $\left.c_{n}^{g o v}\right) /$ Unit: Thousands 


\begin{tabular}{ccc|ccc}
\hline$n$ & 1 & 2 & $n$ & 1 \\
$\operatorname{Cap}_{n}^{\text {min }}$ & 130 & 140 & $c_{n}^{\text {gov }}$ & 0.007 \\
Cap $_{n}^{\text {max }}$ & 330 & 350 & & \\
\hline
\end{tabular}

Table 6. Parameter VI $\left(\delta_{p}, \beta_{p}, \gamma_{p}\right.$, and $\left.\varepsilon_{p}\right)$

\begin{tabular}{c|c|c|c|c}
\hline Category & $\delta_{p} / \%$ & $\beta_{p} / \%$ & $\gamma_{p} / \%$ & $\varepsilon_{p} / \%$ \\
\hline Appliance 1 & {$[15,20]$} & {$[4,7]$} & {$[55,60]$} & {$[13,26]$} \\
Appliance 2 & {$[20,25]$} & {$[5,8]$} & {$[50,55]$} & {$[12,25]$} \\
\hline
\end{tabular}

Table 7. Parameter VII $\left(\eta_{d p}\right.$ and $\left.\eta_{c p}\right)$

\begin{tabular}{cccc|ccccc}
\hline \multirow{2}{*}{ Appliance category } & \multicolumn{3}{c|}{ Part $\eta_{d p}$} & \multicolumn{5}{c}{ Raw material $\eta_{c p}$} \\
\cline { 2 - 9 } & 1 & 2 & 3 & 1 & 2 & 3 & 4 & 5 \\
\hline 1 & $25 \%$ & $45 \%$ & $30 \%$ & $53 \%$ & $6 \%$ & $32 \%$ & $0 \%$ & $9 \%$ \\
2 & $15 \%$ & $40 \%$ & $45 \%$ & $50 \%$ & $0 \%$ & $42 \%$ & $5 \%$ & $3 \%$ \\
\hline
\end{tabular}

Table 8. Parameter VIII $\left(S_{t p k}\right)$

\begin{tabular}{|c|c|c|c|c|c|}
\hline \multirow{2}{*}{$\begin{array}{l}\text { Appliance } \\
\text { category }\end{array}$} & \multirow{2}{*}{$\begin{array}{c}\text { Planning } \\
\text { horizon }\end{array}$} & \multicolumn{4}{|c|}{ Recycle point } \\
\hline & & 1 & 2 & 3 & 4 \\
\hline 1 & $\begin{array}{l}1 \\
2 \\
1 \\
2 \\
\end{array}$ & $\begin{array}{l}{[3883,4271]} \\
{[1941,2136]} \\
{[3448,3695]} \\
{[6034,6465]}\end{array}$ & $\begin{array}{l}{[2315,2546]} \\
{[1157,1273]} \\
{[2244,2404]} \\
{[3926,4207]}\end{array}$ & $\begin{array}{c}{[1763,1939]} \\
{[882,970]} \\
{[1767,1893]} \\
{[3093,3313]}\end{array}$ & $\begin{array}{c}{[1829,2011]} \\
{[914,1006]} \\
{[1361,1458]} \\
{[2382,2552]}\end{array}$ \\
\hline
\end{tabular}

Table 9. Parameter IX $\left(\mathrm{dem}_{t p m}^{ \pm}\right)$

\begin{tabular}{c|c|c|c|c}
\hline \multirow{2}{*}{$\mathrm{b}$} & Planning & \multicolumn{2}{|c}{ Secondary appliance market } \\
\cline { 3 - 4 } & Horizon & 1 & 2 & 3 \\
\hline \multirow{2}{*}{1} & 1 & {$[600,700]$} & {$[700,800]$} & {$[400,500]$} \\
& 2 & {$[150,250]$} & {$[250,350]$} & {$[350,400]$} \\
& 1 & {$[500,600]$} & {$[800,900]$} & {$[600,700]$} \\
\hline
\end{tabular}

Table 10. Parameter X $\left(Q_{m}^{\max } / \pi_{t p m}\right)$

\begin{tabular}{c|c|c|c}
\hline \multirow{2}{*}{ Appliance category } & \multicolumn{3}{|c}{ Secondary appliance market } \\
\cline { 2 - 4 } & 1 & 2 & 3 \\
\hline 1 & $1600 / 15$ & $1500 / 20$ & $1700 / 16$ \\
2 & $2500 / 17$ & $2200 / 18$ & $1900 / 15$ \\
\hline
\end{tabular}

Table 11. Parameter XI $\left(Q_{r}^{\max }\right) /$ Unit: Thousands

\begin{tabular}{|c|c|c|c|}
\hline \multirow{2}{*}{ Part category } & \multicolumn{3}{|c|}{ Part reproducing factory } \\
\hline & 1 & 2 & 3 \\
\hline 1 & 40 & 30 & 50 \\
\hline 2 & 80 & 110 & 90 \\
\hline 3 & 110 & 80 & 100 \\
\hline
\end{tabular}

Table 12. Parameter XII $\left(Q_{s}^{\max }\right) /$ Unit: Thousands

\begin{tabular}{c|c|c|c|c}
\hline \multirow{2}{*}{ Raw material category } & \multicolumn{3}{|c}{ Raw material market } & 3 \\
\cline { 2 - 5 } & 1 & 2 & 16 & 4 \\
2 & 15 & 17 & 4 & 14 \\
3 & 4 & 3 & 11 & 2 \\
4 & 12 & 16 & 1 & 13 \\
5 & 2 & 3 & 2 & 2 \\
\hline
\end{tabular}

Table 13. Parameter XIII $\left(c_{k p}^{g o v}, c_{i p}^{g o v}, c_{j p}^{g o v}\right.$, and $\left.c_{m p}^{g o v}\right)$

\begin{tabular}{c|c|c|c|c}
\hline Appliance Category & $c_{k p}^{g o v}$ & $c_{i p}^{g o v}$ & $c_{j p}^{g o v}$ & $c_{m p}^{g o v}$ \\
\hline 1 & 35 & 2 & 2 & 15 \\
2 & 50 & 3 & 3 & 20 \\
\hline
\end{tabular}




\subsection{Results}

The improved and modified interval linear programming method is realized with LINGO 11.0. The iteration times are 16,656 , and the computational time is $8 \mathrm{~s}$. The global optimal solution is shown in Table 14.

As shown in Table 14, the three alternative transfer stations and the two recycle centers are all open. In addition, the second treatment plant is open. $Y_{1}^{n}=[1,0]$ means that the first treatment plant is only open when the maximum profit of the lower-limit sub-model is available.

Table 14. Optimal solution

\begin{tabular}{c|c|c|c|c}
\hline$Y_{1}^{i}$ & $Y_{2}^{i}$ & $Y_{3}^{i}$ & $Y_{1}^{j}$ & $Y_{2}^{j}$ \\
\hline 1 & 1 & 1 & 1 & 1 \\
\hline$Y_{1}^{n}$ & $Y_{2}^{n}$ & $\sigma_{211}$ & $\sigma_{223}$ & \\
\hline$[1,0]$ & 1 & {$[0,22]$} & {$[0,42]$} & \\
\hline
\end{tabular}

According to aforementioned decisions, the maximum profit of 3PL service providers is $\mathrm{F}=[20454190,20801200]$. Moreover, in the second cycle, shortage occurs. The shortage quantity of household appliance 1 in the secondary market 1 is $[0,22]$. The shortage quantity of household appliance 2 in the secondary market 3 is $[0,42]$. As a result of the space limitations, in this study, we excluded the analyses of the other nodes.

\subsection{Effect of Carbon Tax Scheme}

In this section, the effect of carbon tax is discussed. The carbon tax of unit carbon emission $c_{e}$ is set to 0 to 10 , and the other parameters are unchanged. The model is recalculated, and the results are as follows:

(1) The location strategies of recycle points, transfer stations, and recycle centers are unaffected by carbon tax and remain unchanged. The optimal solution of the interval programming model is robust because the main factor affecting the location strategies is not the carbon tax scheme but the set of acquirable waste household appliance products from recycle points.

(2) The total profit of the reverse logistics network decreases with increasing carbon tax. The total carbon emissions do not increase with increasing carbon tax. The results are summarized in Figs. 2-3.

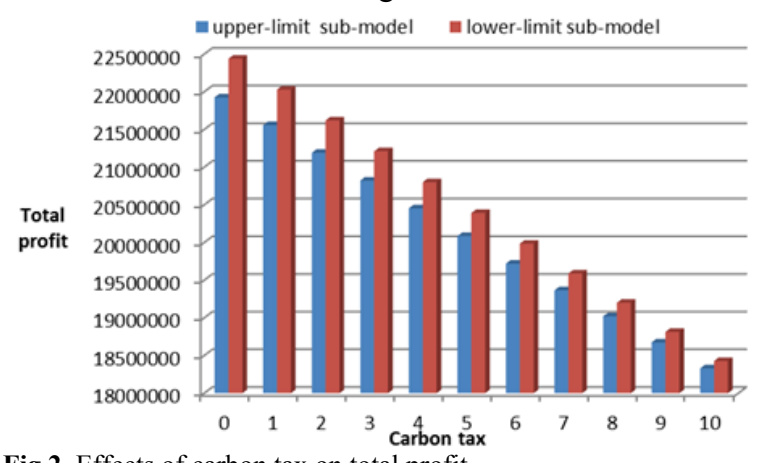

Fig.2. Effects of carbon tax on total profit

As shown in Figs. 2-3, when the carbon tax is relatively low, its effect on 3PL service providers is minimal. The corresponding optimal decisions remain unchanged. Here, the total profit falls within a narrow range, and the total carbon emissions do not decrease. As the carbon tax increases, the optimal decisions are influenced by degrees. The effect should not be ignored. For example, when the carbon tax increases from 5 to 10 , the recycle centers no longer dispose category 1 and category 3 raw materials. Accordingly, the total carbon emissions of the upper-limit and lower-limit sub-models decrease by $6.19 \%$ and $5.57 \%$, respectively. These values pull the total profits of the upperlimit and lower-limit sub- models down to $8.74 \%$ and $9.63 \%$, respectively. These outcomes show that carbon tax significantly influences the decisions of 3PL service providers. Some processing methods should be adjusted to balance economic benefits and the burdens from carbon emissions.

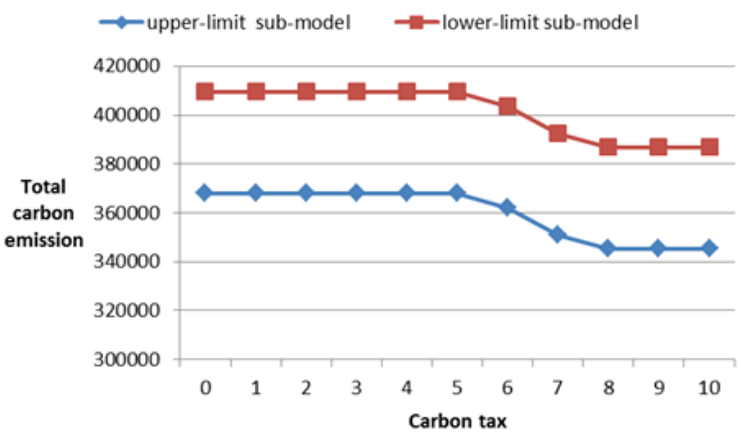

Fig.3. Effects of carbon tax on total carbon emissions

\section{Conclusions}

The high uncertainties of acquirable waste household appliances are a crucial feature of reverse logistics networks. 3PL service providers cannot obtain full knowledge of uncertainties. To design an effective and reasonable 3PL logistics network, we developed a multi-product and multiperiod interval programming model that is used to deal with the trade-off between environmental concerns and economic benefits. The following conclusions were derived from the results of the study:

(1) Through an improved and modified interval linear programming method, the model can be effectively solved, and the optimal interval solution is easily obtained.

(2) The reverse logistics network design policy is robust. With carbon tax changing, the locations of 3PL service providers do not change. Only the flows among different service providers are adjusted. The proposed interval programming model can be conveniently applied to design reverse logistics networks with partial information.

(3) The carbon tax scheme exerts different effects on reverse logistics network design according to carbon tax. When carbon tax is relatively small, its effect is negligible. With increases in carbon tax, the effect significantly increases. When carbon tax is relatively high, carbon emissions can be effectively controlled, but total profits sharply decline. The effect of the carbon tax scheme should not be ignored, and 3PL service providers need to adopt reasonable operation policies to avoid sharp declines in total profit.

The findings of this study provide systematic and formal decision-making support to solve the 3PL reverse logistics network design under a carbon tax scheme. The results also serve as a useful reference for 3PL service providers that seek effective decision making with partial information.

Regarding our future research, we will consider an integrated forward-reverse logistics network design under uncertain environments. In addition, a robust optimization 
Cheng-Hu Yang, Du-Tian Chen, Zhui-Liang Huang and Hai-Bo Liu/

Journal of Engineering Science and Technology Review 9 (5) (2016) 126 - 134

approach to solve interval programming is worth investigating.

\section{Acknowledgements}

This work was supported by the Fujian Provincial Social Science Foundation under Grant FJ2016B059, the Ministry of Education in China, Project of Humanities and Social Sciences under Grant 16YJC790032, and the Fujian Provincial Major Project of Social Science Research under Grant 2014JDZ024.

\section{References}

1. Ali, C. S., F, T.A., and Güvenc, S., "Hybrid simulation-analytica modeling approaches for the reverse logistics network design of a third-party logistics provider", Computers \& Industrial Engineering, 70, 2014, pp. 74-89.

2. Berk, A., Bersam, B., and Nezir, A., "Stochastic reverse logistics network design for waste of electrical and electronic equipment", Resources, conservation and recycling, 104, 2015, pp. 391-440

3. Maria, I. G.S., Ana, P. B., and Augusto, Q. N., "An optimization model for the design of a capacitated multi-product reverse logistics network with uncertainty", European Journal of Operational Research, 179 (3), 2007, pp. 1063-1077.

4. Lee, D. H., and Dong ,M.,"Dynamic network design for reverse logistics operations under uncertainty", Transportation Research Part E, 45 (1), 2009, pp. 61-71.

5. Yang, C.H., Liu, H. B., Ji ,P., and MA, X., "Optimal Acquisition and Remanufacturing Policies for Multi-product Remanufacturing Systems", Journal of Cleaner Production, 135, 2016, pp. 15711579.

6. Smith, V. M., and Keoleian, G.A., "The value of remanufactured engines: life-cycle environmental and economic perspectives", Journal of Industrial Ecology, 8(1-2), 2004, pp. 193-221.

7. Yang, C. H., Bao, X. Y., Song, C., and Liu, H. B., "Optimal Acquisition Policy in Remanufacturing Systems with Quantity Discount and Carbon Tax Scheme", Tehnički vjesnik-Technical Gazette, 23 (4), 2016, pp. 1073-1081.

8. Krikke, H. R., Harten , A. V., and Schuur, P. C., "Business case océ: reverse logistics network re-design for copiers", OR spektrum, 21 (3), 1999, pp. 381-409.

9. Teunter, R., Kaparis, K., and Tang, O., "Multi-product economic lot scheduling problem with separate production lines for manufacturing and remanufacturing", European Journal of Operational Research, 191 (3), 2008, pp. 1241-1253.

10. Kim, H., Yang, J., and Lee, K. D., "Vehicle routing in reverse logistics for recycling end-of-life consumer electronic goods in South Korea", Transportation research part D: transport and environment, 14 (5), 2009, pp. 291-299.

11. Ehab, B., Mohamad, Y.J., and Simone, Z., "A review of mathematical inventory models for reverse logistics and the future of its modeling: an environmental perspective". Applied mathematical modeling, 40 (5-6), 2016, pp. 4151-4178.

12. Moritz, F., Jacqueline , M. B., and Rommert, D., "Quantitative models for reverse logistics: A review", European Journal of Operational Research, 103 (1), 1997, pp. 1-17.
13. Vaidyanathan, J., Raymond, A.P., and Erik, R., "The design of reverse distribution networks: models and solution procedures", European Journal of Operational Research, 105 (1) 2003, pp. 128149.

14. Kara, S., Rugrungruang, F., and Kaebernick, H., "Simulation modeling of reverse logistics networks", International Journal of Production Economics, 106 (1), 2007, pp. 61-69.

15. Sheu, J.B., "A coordinated reverse logistics system for regional management of multi-source hazardous wastes", Computers \& Operations Research, 34 (5), 2007, pp. 1442-1462.

16. Hatefi, S. M., and Jolai, F., "Robust and reliable forward-reverse logistics network design under demand uncertainty and facility disruptions", Applied Mathematical Modelling, 38 (9-10), 2014, pp. 2630-2647.

17. Kannan,G., Parichehr, P., and Abtahi, A. R., "A fuzzy multiobjective optimization model for sustainable reverse logistics network design", Ecological Indicators, 67, 2016, pp. 753-768.

18. Lee, D. H., Bian, W., and Dong, M., "Multi-objective model and solution method for integrated forward and reverse logistics network design for third-party logistics providers", Transportation research record: Journal of the transportation research board, 20 (32), 2007, pp.43-52.

19. Hyun, J. K., and Gerald, W.E., "A genetic algorithm-based heuristic for the dynamic integrated forward/reverse logistics network for 3PLs", Computers \& Operations Research, 34, 2007, pp. 346-366.

20. Mortiz, F., Hans, R. K., and Rommert, D., "A characterisation of logistics network for product recovery", Omega, 28 (6), 2000, pp. 653-666.

21. Yang, C. H., Wang, J., and Ji, J. P., "Optimal acquisition policy in remanufacturing under general core quality distributions", International Journal of Production Research, 53 (5), 2015, pp. 1425-1438.

22. Huang, G., Baetz , B. W., and Patry, G. G., "A grey linear programming approach for municipal solid waste management planning under uncertainty", Civil Engineering Systems, 9 (4), 1992, pp. 319-335

23. Allahdadi, M., Nehi, H. M., and Ashayerinasab, H. A., "Improving the modified interval linear programming method by new techniques", Information Sciences, 339, 2016, pp. 224-236.

24. Harold, K., "Impact of closed-loop network configurations on carbon footprints: A case study in copiers", Resources, conservation and recycling, 55, 2011, pp. 1192-1205.

25. Devika, K., Ali, D., Mahmoud, A., Kannan, G., and Geng, Y., "A carbon footprint based reverse logistics network design model", Resources, conservation and recycling, 67, 2012, pp. 75-79. 